\title{
INTEGRATED WASTE MANAGEMENT: ENVIRONMENTAL ASSESSMENT AND PLANNING
}

\author{
G. PERILLO \\ Department of Technology, Naples Parthenope University, Italy.
}

\begin{abstract}
An important aspect - although not the only one - in planning and developing a system for waste management is to optimise environmental benefits and minimise environmental damage. The purpose of this contribution is to outline a common approach to evaluating environmental impacts - Life Cycle Assessment (LCA) - and to show how it can be used in structured processes to plan and develop waste management policies and systems. LCA, also sometimes known as 'Cradle-to-Grave' Assessment, is a general approach to evaluating the total environmental impacts of providing a product or service [1]. Keywords: life cycle assessment, management, waste.
\end{abstract}

\section{INTRODUCTION}

The basic approach to managing and regulating an industrial process is to examine the flows of energy and materials into and out of the plant and also the wastes and emissions arising out of it (Fig. 1). This approach is sometimes called Integrated Pollution Control (IPC): it is 'integrated' in the sense that it considers emissions to all receiving media, that is, to air, water and land. By contrast, life cycle assessment (LCA) considers the whole supply chain, including the original sources of the materials and energy, and also the use of the product and re-cycling or disposal after use. One of the reasons for using LCA is to ensure that changes to the process intended to improve its environmental performance do not merely transfer environmental impacts or resource inputs to other parts of the supply chain - a phenomenon known as burden shifting.

As an obvious example, removing a boiler or generating plant from the process and importing electricity instead will usually reduce the direct wastes and emissions from the process but at the expense of increased wastes and emissions elsewhere in the energy supply system.

One of the features of LCA is that, correctly applied, it gives a complete picture of the environmental impacts of providing a product or service but without giving sufficient information to support decisions on where a particular process should be located: that is, it supports the choice of the technology to be used but not the site where a plant should be built. Figure 2 shows schematically the types of decisions that normally have to be made, in general taking into consideration the specific case of waste management. LCA is the appropriate tool to support the choice of technology when the site has not been selected (Case A) or the choice of technology to be used at an identified site (Case C). A completely different tool - some form of Environmental Impact Assessment (EIA) - is appropriate where the technology is known but it is necessary to decide where to locate it (Case B). Where both the technology and the site must be chosen (Case D), a combination of LCA and EIA must be used. 
230 Environmental and Economic Impact on Sustainable Development

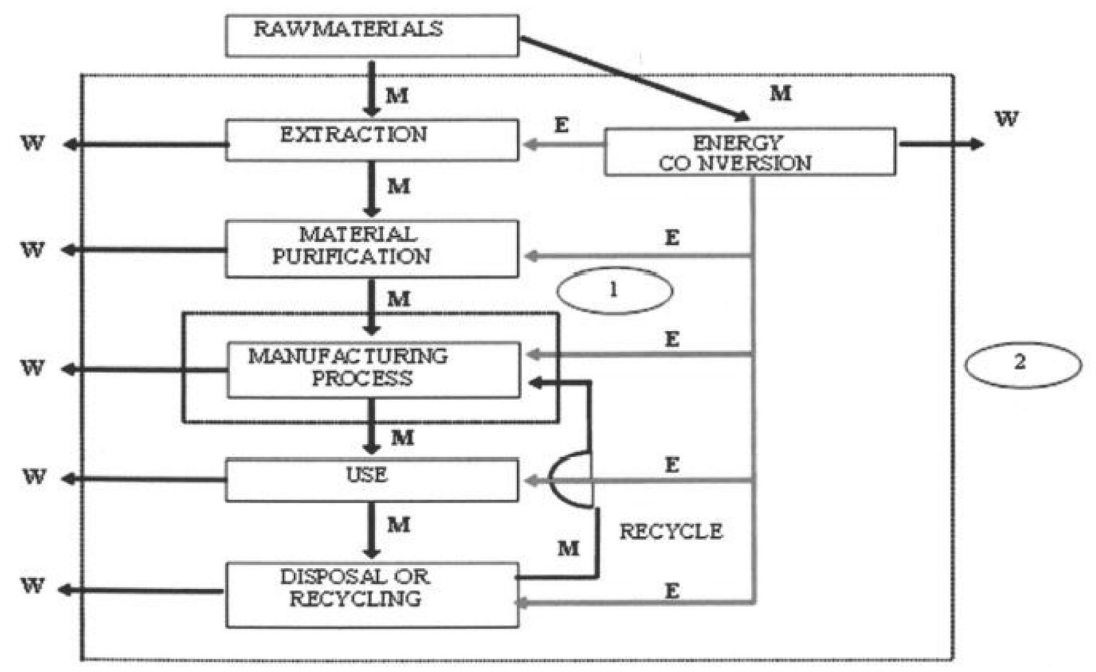

Figure 1: The basis of life cycle assessment. $1=$ Integrated Pollution Control (IPC), $2=$ LCA

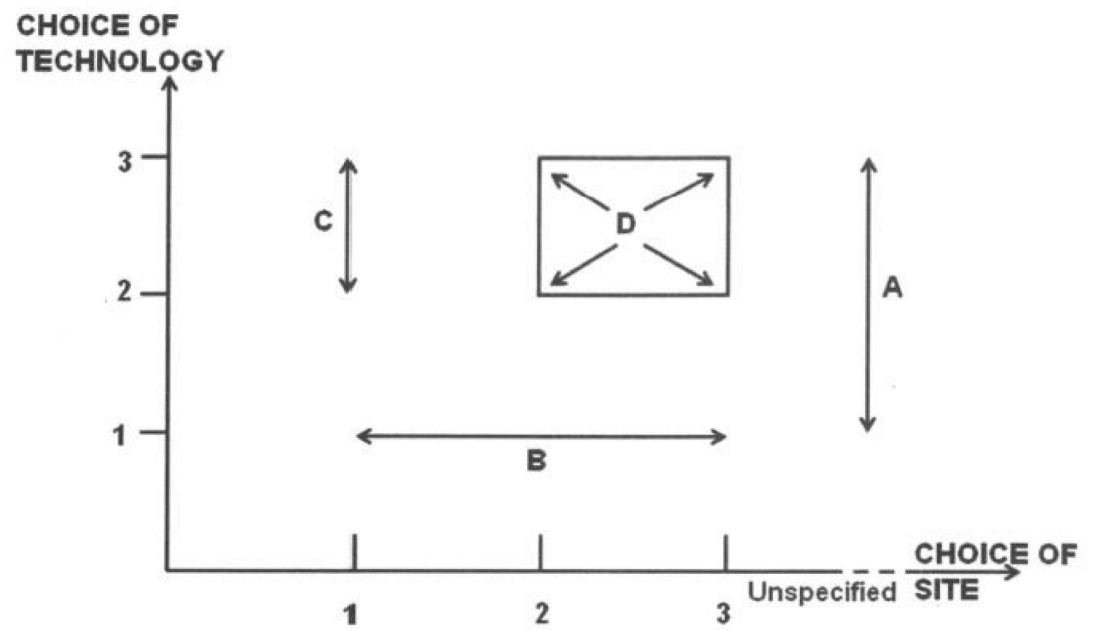

Figure 2: Life cycle assessment and environmental impact assessment.

\section{LCA AS A GENERAL TOOL}

The development of an LCA as a general tool for analysing the environmental performance of industrial systems dates from the 1970s. By the 1990s, it had become apparent that some standardisation of approach was needed to ensure that the tool could not be distorted to make spurious claims about environmental performance. The first international standards - ISO 14040: Environmental Management — LCA - Principles and framework - was published in 1997. Subsequent standards dealing with how LCA is to be applied were consolidated as ISO 14044: Environmental Management - LCA - Requirements and Guidelines, published in 2006. According to ISO standards, carrying out an LCA involves the distinct phases shown in Fig. 3. 


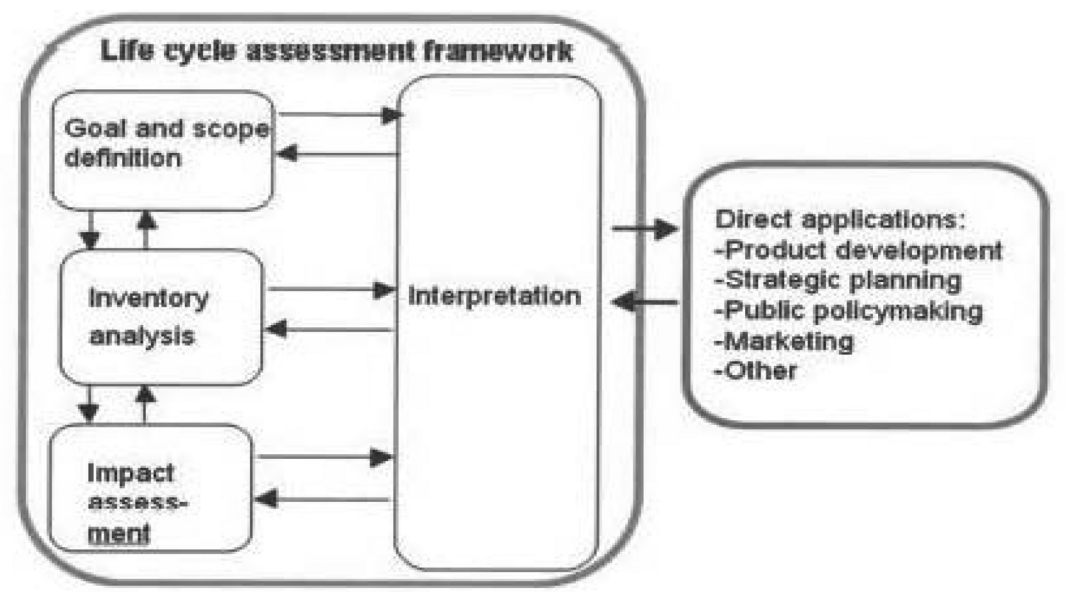

Figure 3: Phases in execution of a LCA.

Goal and Scope Definition: At the outset, it is necessary to define clearly the goal and scope of the study: for example, is it to identify the main causes of an environmental impact in a supply chain? Or is it to compare alternative technologies that deliver the same function or service? In this case, processes common to the systems compared can be omitted. This will determine the extent of the system which the LCA must cover; that is, it will lead to definition of the system boundary. It is also essential to define the functional unit; that is, the quantity of the product or service on which the study is based. It is also useful at this stage to distinguish between the set of activities that make up the Foreground System (i.e. the set of processes whose selection or mode of operation is affected directly by decisions based on the study) and the Background System (comprising all other processes that interact directly with the foreground system, usually by supplying materials or energy to the foreground or receiving materials or energy from it).

As shown in Fig. 4, the next phase in conducting the LCA is Inventory Analysis, in which all the inputs of primary resources (including energy and fuels) and outputs of waste and emissions are identified and quantified in the form of an inventory table. Emissions to the atmosphere, to the water system and to land or ground-water must be included separately, going to the level of detail of distinguishing between different chemical compounds. This is usually a very labour-intensive task. It is helped by the distinction between Foreground and Background: the inventory for the foreground is normally based on primary data, that is, direct measurement or design figures for the foreground operations, but it is usually considered adequate to describe the background by average data for the economy in which the foreground system is embedded. A number of databases are available to provide secondary background data; this significantly reduces the time and effort needed to compile the inventory table.

The result of the inventory analysis is an inventory table containing a large body of data, usually too detailed to provide the basis for interpretation of the outcome of the study. It is, therefore, followed by the phase termed Life Cycle Impact Assessment (LCIA), in which the inventory table is translated into quantified contributions of a set of recognised impact categories, including resource use. In general, LCA has been developed to describe global impacts rather than specific effects. Figure 5 summarises the approach taken in LCIA. For 
232 Environmental and Economic Impact on Sustainable Development

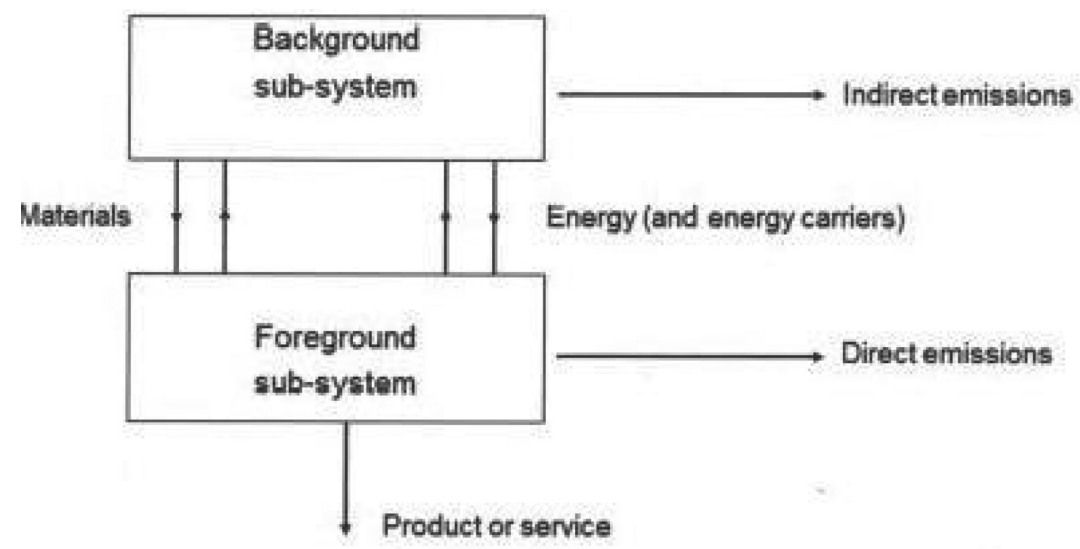

Figure 4: Foreground and background (sub) systems.

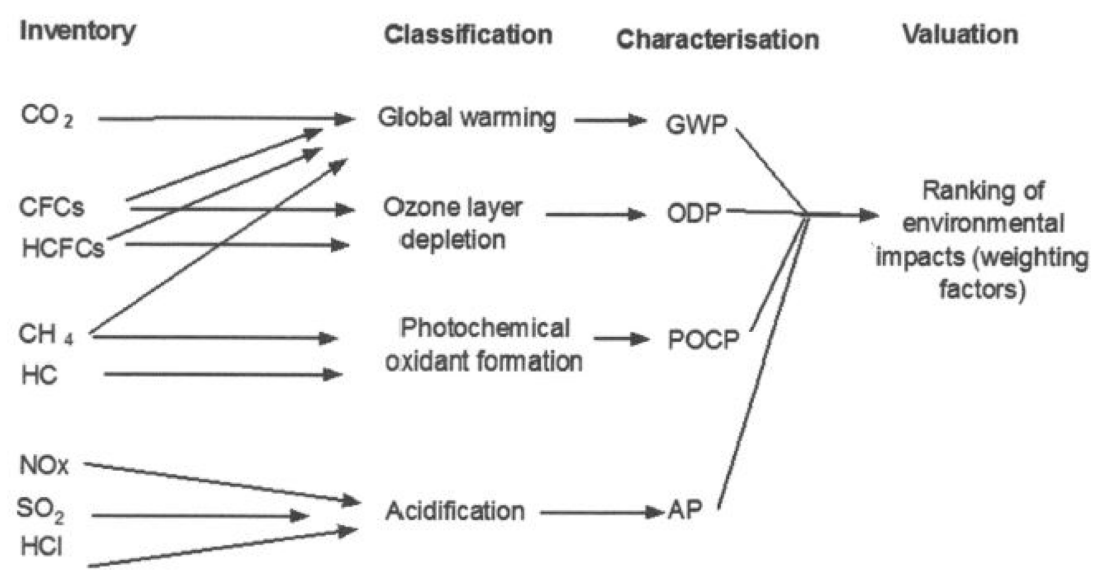

Figure 5: Life cycle impact assessment.

example, the impact of carbon dioxide emission features only in the category global warming. Emissions of chloro-fluoro-carbons (CFCs), formerly used as refrigerants, primarily cause ozone layer depletion but also contribute to global warming. Hydro-chloro-fluoro-carbons (HCFCs), which were introduced as substitutes for the ozone-depleting CFCs, have a much reduced effect on stratospheric ozone but at the expense of a substantial contribution to global warming. The emissions that are classified as contributing to global warming, for example, are then characterised by weighing them according to their Greenhouse Warming Potential (GWP) relative to the reference compound, which is carbon dioxide for this impact category. Summing the contributions gives the total contribution of the life cycle to global warming, expressed as an equivalent quantity of carbon dioxide per functional unit.

This approach to LCIA converts the extensive inventory table into a much smaller and, therefore, more intelligible, set of environmental impacts that are intended to meet the goal of the study. Some studies aggregate the impacts into a single environmental impact score by 
weighting and adding them in the process termed Valuation. The weighting factors are commonly given by estimates of the economic damage cost for each impact category. However, there are arguments, introduced later in this article, against carrying out Valuation. An alternative is to explore the significance of the different impacts by normalising them, by expressing each as a fraction of the impacts of all human activities globally or in some geographical or economic area. Common experience is that normalisation identifies a small number of impacts - frequently only two or three - as dominating the impacts of the life cycle.

LCA as a general tool has become firmly embedded in environmental policy, notably in the European Union. It also provides the basis for consumer labels, including ecolabels which are intended to identify products and services with improved environmental performance and footprint labels which show, for example, the total quantity of greenhouse gas emissions from the supply chain (i.e. the carbon footprint) or the total quantity of water used (i.e. the water footprint).

\section{APPLYING LCA TO WASTE MANAGEMENT}

LCA is also established as a tool to guide the development of waste management policies and systems, although this requires some adaptation of the general approach outlined in the previous section [2].

It is usual to define the functional unit for the study as the treatment of a defined quantity of waste or the waste from a defined area or number of households. Thus, rather than being a truly cradle-to-grave analysis, the system studied begins at the point where a material becomes defined as waste and does not include the activities that generate the waste). The waste management operations, including transport, then make up the foreground system, while the background is the rest of the economy that provides energy (e.g. electrical power) and materials (e.g. transport fuel) to the foreground waste management activities, or receives material or energy recovered from the waste (e.g. energy recovered as electricity and/or steam generated by thermal treatment of waste).

The usual assumption is that the other outputs from the background economy are unaffected by the waste treatment, so that materials or energy recovered from waste offsets production in the background. This enables the credits for material or energy recovery to be calculated on a consistent basis [3]. The total inventory for the foreground waste management system is calculated as:

- Direct burdens arising from the foreground processes;

- Adding Indirect burdens arising from materials and energy provided to the foreground; and

- Deleting Avoided burdens displaced from the background by materials and energy recovered from waste in the foreground.

Impact assessment is carried out in the usual way. The impacts revealed by normalisation as most significant invariably include global climate change. Where waste is land-filled, emissions of methane are commonly significant contributors to this impact. Of the impacts listed, toxicity is usually important, arising from leakage of leachates from landfills or atmospheric emissions from thermal treatment. Less obviously quantifiable impacts include noise, odour and disruption due to traffic movements. 
234 Environmental and Economic Impact on Sustainable Development

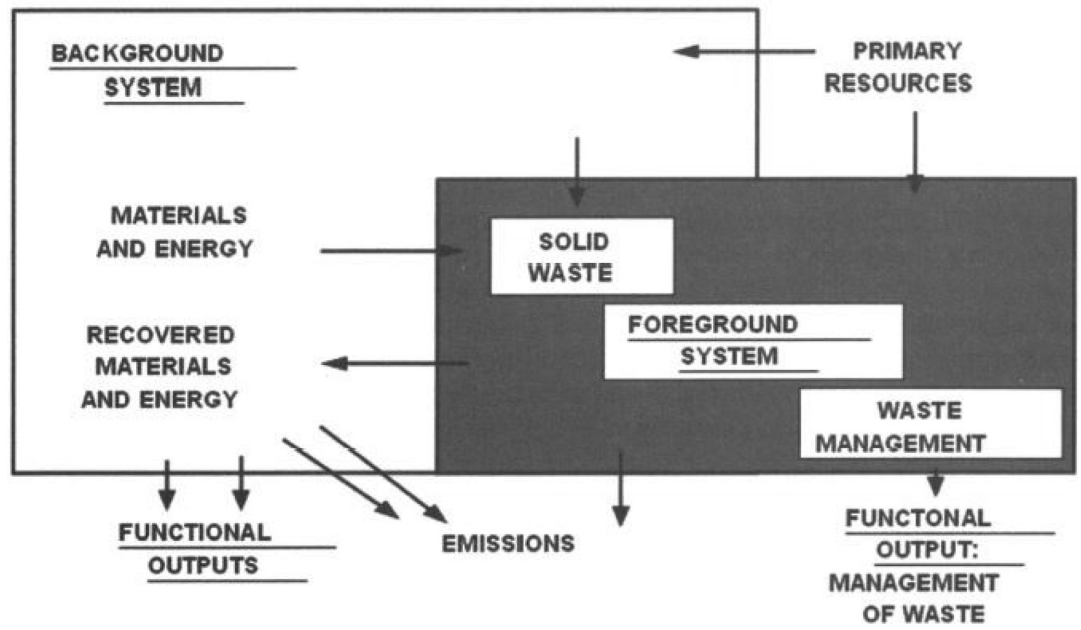

Figure 6: Foreground and background in waste management.

\section{USING ENVIRONMENTAL INFORMATION IN PUBLIC SECTOR DECISIONS}

LCA was originally developed as an expert technical tool. Insensitive use of the tool or the results has, in the past, provoked some opposition to using LCA in decisions like those involved in waste management. To explore why this is so and how to use LCA to better effect, it is necessary to introduce some ideas from decision theory. A classification of decisions from the field of multi-objective optimisation is helpful. It is summarised here in Fig. 7. A fundamental distinction is made between two classes of multi-objective decision problems:

- Single Decision-maker Problems in which the decision is to be made either by one individual or by a group who share the same concerns. In practice, the key characteristic of this class is not whether the decision rests with a single individual. Rather, it is that the criteria on which the decision is to be based have been agreed in advance - that is, on whether some normative process (which might be explicit or implicit) has been followed to define the criteria for the decision.

- Multiple Decision-maker Problems where the decision is 'open': that is, the decision criteria are not defined in advance, even implicitly. Rather, they have to be elicited in the course of the decision process. Decisions in the public sector - for example, decisions over how to treat solid waste - are usually in the multiple decision-maker category.

Within the single decision-maker category, there is a further distinction between decisions with and without prior articulation of preferences. The case with articulated preferences describes decisions where not only have the criteria been defined, they have also been assigned weights or scores or ranks that quantify the extent to which performance against one criterion can be 'traded off' against some other objective. In LCA, this process corresponds to the Valuation phase. The widespread approach of Cost-Benefit Analysis also falls into this category: all measures of performance or impact are reduced to a single metric, expressed in monetary terms, so that the decision process is reduced to selecting or optimising a single objective [4].

The category single decision-maker without articulated preferences describes cases in which the criteria for the decision are agreed in advance, explicitly or implicitly, but the 


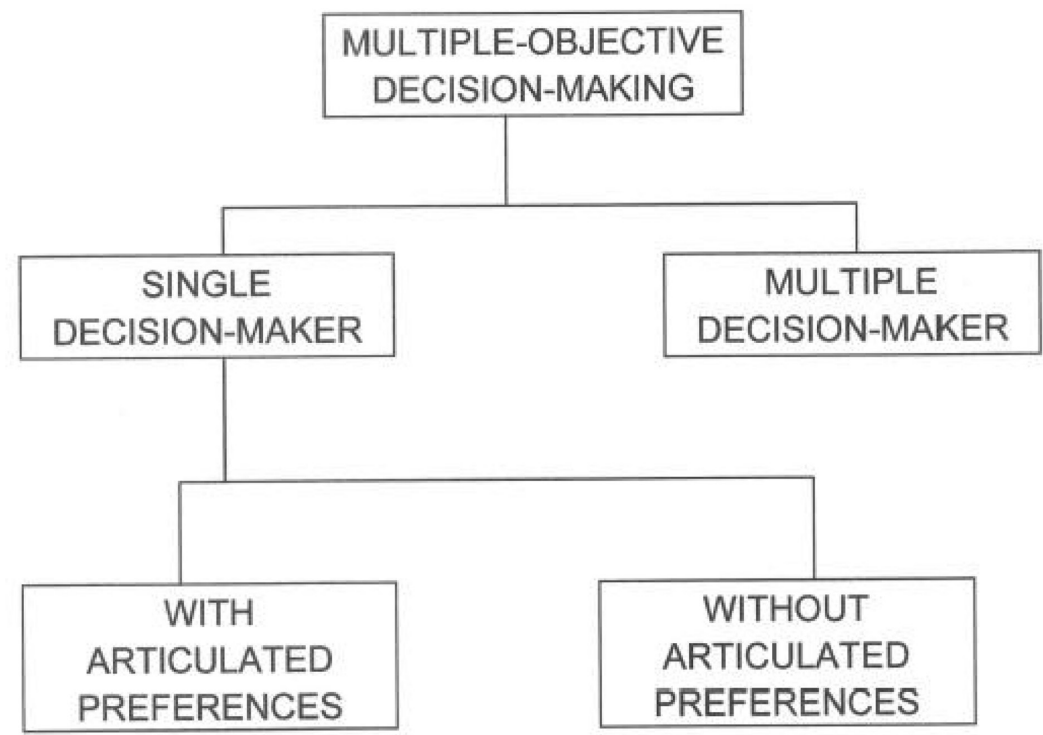

Figure 7: Classification of multiple-objective decisions.

'trade-offs' between different objectives are considered explicitly in reaching a decision rather than being reduced in advance to a single objective functions [5]. LCA without valuation readily lends itself to this kind of decision.

The classification summarised in Fig. 7 helps to understand why it is important to match the process of reaching a decision to the type of decision to be made, using the principle of proportionality - fitting the approach and tools to the purpose in hand.

Decisions within a commercial organisation are usually in the single decision-maker category. The decision criteria relate to the economic performance of the company, defined narrowly or with a longer-term perspective - Net Present Value of a project, return on investment, shareholder value and so on.

Routine processes requiring many discrete decisions are best treated as single decisionmaker problems with prior articulation of preferences. Development and design of manufactured products are typical of this category, requiring many decisions over selection of components and materials. For this reason, design-for-the-environment - a systematic approach to improving the environmental performance of manufactured products, allowing for the life cycles of all the constituent materials - uses measures of environmental impact aggregated to a single number.

Decisions that have major commercial or strategic implications but which lie within a single company or organisation are best treated as single decision-maker problems without prior articulation of preferences. Corporate investment decisions are usually addressed in this way. Selection and design of processes are also in this class; the approach summarised above to incorporate environmental criteria into these decisions recognises the classification explicitly.

\section{CONCLUSIONS}

Multiple decision-maker problems represent the most difficult class. However, decisions in the public sector - for example, planning decisions or decisions over waste management policy - are usually in this category. Failure to recognise this, and trying to use a simpler 
process that is actually designed for single decision-maker problems, can lead to spectacular failure of the decision process. In the public sector, attempts to quantify 'social preferences' by establishing the significance which the general public attaches to a range of scientifically constructed environmental impact categories often fail because they are conceptually misconceived: if 'the public' is not party to the normative process that defines the decision criteria they are being asked to weight criteria that may not correspond to public values or preferences; this is another example of trying to force multiple decisionmaker problems into the single decision-maker mould. Furthermore, these methodological issues are overlaid by fundamental questions as to whether it is necessary or conceptually valid to reduce categorically different criteria to a single metric, particularly by monetary valuation.

Discussions over waste management strategies and technologies and over the siting of facilities are clearly in the multiple decision-maker category of Fig. 7. EIA has developed a general approach or process for such decisions. LCA has to be applied in the same kind of way. Input by the non-expert public is needed at all stages in the analysis, starting with goal, scope and system definition. This may come as something of a culture shock to anyone accustomed to working in the private sector where decisions are in the single decision-maker class and, therefore, not normally subject to public engagement or scrutiny [6]. Ideally, the decision process requires the entire analysis to involve all stakeholders, where a stakeholder is defined as an individual or an organisation with a legitimate interest in the decision. Legitimacy is deliberately left undefined - 'interest' is to be legitimated by acceptance from other parties to the process. The hope is that proceeding in this way will exclude extreme, unrepresentative or narrow single-obsession views (along with outright 'nutters').

So, according to this model of a decision process, technical experts must expect to present their assessments to lay bodies which will consider this evidence, along with other expert evidence, as part of a process that reaches a decision in the light of the stakeholder values elicited in the course of the deliberation process. The process should also provide an audit trail which records the path by which the outcome was reached. Especially where a citizens' jury is convened to reach a decision on a major planning issue, the whole process starts to resemble a litigation involving experts as witnesses.

A common reaction to the suggestion that decisions should be addressed by such a deliberative process is reluctance: 'it would take too long', 'we can't afford it' or some extreme rejection along the lines of 'the public don't / won't understand the issues'. However, there is a considerable body of experience confirming that a properly planned and facilitated public process can actually save time and money (and that the general public is well able to 'understand the issues' if they are presented appropriately). As a specific example, counties in the United Kingdom which embraced deliberative decision making have well developed and widely accepted waste management systems whereas some counties which approached waste policy as a single decision-maker problem are still struggling to develop strategic plans and are far short of implementation. If the objective is to get clean and efficient waste management processes that can be accepted and used, then it makes sense to devote effort to developing effective decision processes as well and to ensure that the technical input to these processes, including environmental assessment by LCA, is transparent and open. 


\section{REFERENCES}

[1] Baumann, H. \& Tillman, A.M., The Hitch-hiker's Guide to LCA, Studentlitteratur, Lund, 2004.

[2] Clift, R., Doig, A. \& Finnveden, G., The application of life cycle assessment to integrated solid waste management: part 1-methodology. Process Safety and Environment Protection, 78, pp. 279-287, 2000. http://dx.doi.org/10.1205/095758200530790

[3] Weidema, B., Avoiding co-product allocation in life cycle assessment. Journal of Industrial Ecology, 4(3), pp. 11-33, 2010. http://dx.doi.org/10.1162/108819800300106366

[4] Elghali, L., Clift, R., Begg, K.G. \& McLaren, S., Decision support methodology for complex contexts. Engineering Sustainability, 161, pp. 7-22, 2008. http://dx.doi.org/10.1680/ensu.2008.161.1.7

[5] Clift, R., Sustainable development and its implications for chemical engineering. Chemical Engineering Science, 61, pp. 4179-4187, 2006. http://dx.doi.org/10.1016/j.ces.2005.10.017

[6] Mitchell, C.A., Carew, A.L. \& Clift, R., The role of the professional engineer and scientist in sustainable develropment. Sustainable Development in Practice, Wiley \& Sons: Chichester, 2004. 